\title{
Stimulation of Aflatoxin Biosynthesis by Lipophilic Epoxides
}

\author{
By C. FANELLI, ${ }^{*}$ A. A. FABBRI, ${ }^{1}$ E. FINOTTI ${ }^{1}$ AND S. PASSI ${ }^{2}$ \\ ${ }^{1}$ Botanical Garden Institute, Rome University, Largo Cristina di Svezia 24, 00165 Rome, Italy \\ ${ }^{2} S$. Gallicano Institute, Rome, Italy
}

(Received 6 October 1982; revised 22 December 1982)

Epoxy fatty acids added to the culture media either with the inoculum or at the end of exponential growth phase stimulated aflatoxin production by toxigenic strains of Aspergillus flavus and Aspergillus parasiticus. This effect did not appear when the unsaturated fatty acids used for the synthesis of the epoxides and the polyhydroxyacids (which can be considered to be derived from the opening of the oxirane ring) replaced the epoxides in the culture media. No significant differences were detected in the lipid fractions (diglycerides, sterols, triglycerides, free fatty acids, sterol esters) extracted from the mycelia grown in the presence of any of the fatty acid derivates.

\section{INTRODUCTION}

In a previous report we have described the stimulating effect of two inhibitors of fatty acid synthetase (cerulenin and tetrahydrocerulenin) on aflatoxin production (Fanelli et al., 1983). This stimulating effect appeared when these compounds were added to exponential phase fungal cultures. As two analogues of cerulenin that do not inhibit fatty acid synthetase (D'Agnolo et al., 1973) did not show the same effect as cerulenin, we have determined whether stimulation of aflatoxin production could be related to the epoxide structure present in cerulenin and tetrahydrocerulenin and absent in the two analogues (di- and hexahydrocerulenin). Thus we have studied the effect of methyl 9,10 epoxystearate and methyl 9,10:12,13 diepoxystearate on the biosynthesis of aflatoxins.

\section{METHODS}

Fungus culture. Aspergillus parasiticus (strain NRRL 2999) was normally grown in $50 \mathrm{ml}$ Czapek Dox broth medium $+5 \mathrm{mg} \mathrm{ZnSO}_{4} \mathrm{l}^{-1}$ and $1 \mathrm{mg} \mathrm{Na} \mathrm{MoO}_{4} \mathrm{l}^{-1}$ in $100 \mathrm{ml}$ conical flasks at $30^{\circ} \mathrm{C}$. The inoculum was $10^{6}$ conidia from 15 d old culture grown on Czapek Dox agar medium. Similar experiments used strains of Aspergillus favus (ATCC 22548 and CF1) as in our previous papers (Fanelli et al., 1980, 1981).

Chemicals. Oleic acid, linoleic acid, oleic acid methyl ester and linoleic acid methyl ester were obtained from Sigma. The solvents for HPLC were Lichrosorb from Merck. All other chemicals were reagent grade.

Synthesis of epoxides. The synthesis of epoxides was carried out according to the methods described by Pocar (1966) with slight modifications. The methyl 9,10 epoxystearate and methyl $9,10: 12,13$ diepoxystearate were obtained from methyl oleate and methyl linoleate with perbenzoic acid prepared from benzylperoxide (0.21 mol) by treatment with a solution of sodium methoxide $(0.22 \mathrm{~mol})$.

Oleic acid methyl ester $(10 \mathrm{mmol})$ was allowed to react in $150 \mathrm{ml}$ diethylether with $10.5 \mathrm{mmol}$ perbenzoic acid at $0{ }^{\circ} \mathrm{C}$ for $24 \mathrm{~h}$ with occasional shaking. The reaction mixture was washed five times with $20 \mathrm{ml}$ portions $10 \%$ (w/v) $\mathrm{NaOH}$, three times with distilled water and dried over anhydrous $\mathrm{MgSO}_{4}$. The methyl 9,10 epoxystearate was recovered after evaporation of the solvent under reduced pressure in a rotary evaporator at below $30^{\circ} \mathrm{C}$ and further purified on silica gel column ( $\mathrm{Si} 60$ ) using $20 \%$ diethylether $/ 80 \%$ petroleum ether as elution solvents. The methyl 9,10:12,13 diepoxystearate was prepared as described for methyl 9,10 epoxystearate by treatment of $10 \mathrm{mmol}$ methyl linoleate with $21 \mathrm{mmol}$ perbenzoic acid at $0{ }^{\circ} \mathrm{C}$ for $24 \mathrm{~h}$.

Synthesis of hydroxyacids. The 9,10 dihydroxystearic acid and 9,10:12,13 tetrahydroxystearic acid were obtained by performic acid oxidation followed by alkaline hydrolysis of fatty acid methyl esters (Pasi et al., 
$1981 \mathrm{a}$ ). Methyl oleate $(1 \mathrm{~g})$ was allowed to react with $15 \mathrm{ml}$ formic acid plus $2 \mathrm{ml} 30 \% \mathrm{H}_{2} \mathrm{O}_{2}$ at $40{ }^{\circ} \mathrm{C}$ for $2 \mathrm{~h}$ with occasional shaking. The reaction mixture was diluted with $50 \mathrm{ml}$ distilled water and extracted three times with $30 \mathrm{ml}$ portions of peroxide-free diethylether. The extracts were pooled and the ether evaporated under reduced pressure in a rotary evaporator at below $30^{\circ} \mathrm{C}$. The product was saponified in $20 \mathrm{ml} 3 \mathrm{M}-\mathrm{NaOH}$ at $100^{\circ} \mathrm{C}$ for about $30 \mathrm{~min}$, acidified at $\mathrm{pH} 2-3$ with diluted $\mathrm{H}_{2} \mathrm{SO}_{4}$ and extracted as before with diethylether. The 9,10:12,13 tetrahydroxystearic acid was prepared as described for 9,10 dihydroxystearic acid by treatment of $1 \mathrm{~g}$ methyl linoleate with $30 \mathrm{ml}$ formic acid plus $4 \mathrm{ml} \mathrm{30 \%} \mathrm{H}_{2} \mathrm{O}_{2}$. Note that the opening of oxirane rings under basic or acid conditions is an $\mathrm{SN}_{2}$ reaction, which produces trans-glycol. The pooled extracts containing saturated dihydroxyand tetrahydroxystearic acids were evaporated to dryness under reduced pressure in a rotary evaporator.

Estimation of the fungal growth. Fungal growth was estimated by mycelium dry weight obtained after drying at $80^{\circ} \mathrm{C}$ for $48 \mathrm{~h}$. The mycelium was previously filtered on Millipore filters (pore size $0.45 \mu \mathrm{m}$ ) and washed three times in saline $(\mathrm{NaCl} 0.9 \%, \mathrm{w} / \mathrm{v})$.

Analysis of lipids. The total lipids of the mycelium were extracted with $\mathrm{CHCl}_{3} / \mathrm{CH}_{3} \mathrm{OH}(2: 1, \mathrm{v} / \mathrm{v})$ for $3 \mathrm{~h}$ and separated into their various components by TLC as described (Fanelli et al., 1983).

Analysis of aflatoxins. The aflatoxins were extracted with $\mathrm{CHCl}_{3} / \mathrm{CH}_{3} \mathrm{OH}(2: 1, \mathrm{v} / \mathrm{v})$ both from mycelium and culture filtrate (Fanelli et al., 1981) and analysed by TLC and HPLC (Fanelli et al., 1983).

Statistics. Data are presented as mean \pm S.E.M. Differences from the control were evaluated by Student's test for unpaired data. Linear regression was calculated by method of least squares and their significance tested by estimating the correlation coefficient $r^{2}$.

\section{RESULTS AND DISCUSSION}

Table 1 shows the effect of different lipid supplements added to the culture media at the end of the exponential growth phase (day 6) of the toxigenic strain of $A$. parasiticus (NRRL 2999). Among all the compounds assayed only those with epoxide ring (methyl 9,10 epoxystearate and methyl $9,10: 12,13$ diepoxystearate) showed an evident stimulating effect (200 times more than the control) on aflatoxin production. The stimulating effect was much more striking than that observed with cerulenin and tetrahydrocerulenin (Fanelli et al., 1983). Neither the fatty acids used for the synthesis of the epoxides (oleic acid, oleic acid methyl ester, linoleic acid, linoleic acid methyl ester) nor the polyhydroxyacids (which can be considered to be derived from the opening of the oxirane ring) showed any effect on aflatoxin production.

\section{Table 1. Aflatoxin production, growth and total lipids extracted from mycelium by A. parasiticus at $30^{\circ} \mathrm{C}$}

All the compounds were added to the culture medium on day 6 of fungal growth. Aflatoxin production is expressed as $\mu \mathrm{g}$ total aflatoxins (extracted from mycelium and from culture filtrate) per flask. Total lipid is expressed as $\mathrm{mg}$ total lipids extracted from mycelium per $\mathrm{mg}$ dry weight of mycelium $\times 100$.

\begin{tabular}{|c|c|c|c|c|c|c|}
\hline \multirow[b]{2}{*}{ Lipid supplement } & \multicolumn{3}{|c|}{ Day 8} & \multicolumn{3}{|c|}{ Day 10} \\
\hline & $\begin{array}{l}\text { Aflatoxin } \\
(\mu \mathrm{g})\end{array}$ & $\begin{array}{l}\text { Dry wt of } \\
\text { mycelium } \\
(\mathrm{mg})\end{array}$ & $\begin{array}{l}\text { Total } \\
\text { lipid } \\
(\%)\end{array}$ & $\begin{array}{l}\text { Aflatoxin } \\
(\mu \mathrm{g})\end{array}$ & $\begin{array}{l}\text { Dry wt of } \\
\text { mycelium } \\
\text { (mg) }\end{array}$ & $\begin{array}{l}\text { Total } \\
\text { lipid } \\
(\%)\end{array}$ \\
\hline & $2.5 \pm 0.7$ & $290 \pm 22$ & $18 \cdot 0 \pm 5 \cdot 6$ & $2 \cdot 2 \pm 0 \cdot 5$ & $275 \pm 18$ & $17 \cdot 7 \pm 4 \cdot 7$ \\
\hline $\operatorname{cid}\left(1 \mathrm{mg} \mathrm{ml}^{-1}\right)$ & $2 \cdot 0 \pm 0 \cdot 3$ & $311 \pm 36$ & $19 \cdot 1 \pm 6 \cdot 1$ & $2 \cdot 3 \pm 0.4$ & $321 \pm 29$ & $18 \cdot 6 \pm 5 \cdot 5$ \\
\hline $\begin{array}{l}\text { cid methyl ester } \\
\left.\mathrm{ml}^{-1}\right)\end{array}$ & $2 \cdot 4 \pm 0.7$ & $302 \pm 36$ & $18 \cdot 0 \pm 5 \cdot 4$ & $2 \cdot 2 \pm 0.6$ & $316 \pm 39$ & $17.8 \pm 4.9$ \\
\hline$c$ acid $\left(0.5 \mathrm{mg} \mathrm{ml}^{-1}\right)$ & $2 \cdot 6 \pm 0.5$ & $337 \pm 41$ & $19 \cdot 4 \pm 7 \cdot 7$ & $2 \cdot 3 \pm 0 \cdot 4$ & $327 \pm 35$ & $19 \cdot 2 \pm 5 \cdot 2$ \\
\hline $\begin{array}{l}\text { ic acid methyl ester } \\
\text { ng } \mathrm{ml}^{-1} \text { ) }\end{array}$ & $2 \cdot 2 \pm 0 \cdot 3$ & $315 \pm 42$ & $18.9 \pm 4.2$ & $2 \cdot 0 \pm 0 \cdot 3$ & $300 \pm 27$ & $18.8 \pm 5.6$ \\
\hline $\begin{array}{l}\text { poxymethylstearate } \\
\mathrm{ml}^{-1} \text { ) }\end{array}$ & $12 \cdot 4 \pm 4 \cdot 6^{*}$ & $264 \pm 19$ & $19 \cdot 8 \pm 6 \cdot 3$ & $233 \cdot 1 \pm 35 \cdot 5^{*}$ & $387 \pm 31$ & $20 \cdot 8 \pm 6 \cdot 1$ \\
\hline $\begin{array}{l}2,13 \text { Diepoxymethyl- } \\
\text { ate }\left(0.5 \mathrm{mg} \mathrm{ml}^{-1}\right)\end{array}$ & $188.2 \pm 33.8^{*}$ & $244 \pm 31$ & $20 \cdot 1 \pm 6 \cdot 6$ & $261 \cdot 4 \pm 27 \cdot 2^{*}$ & $374 \pm 36$ & $21 \cdot 5 \pm 6 \cdot 7$ \\
\hline $\begin{array}{l}\text { ihydroxystearic acid } \\
\mathrm{ml}^{-1} \text { ) }\end{array}$ & $3 \cdot 1 \pm 0.8$ & $308 \pm 40$ & $18 \cdot 5 \pm 5 \cdot 5$ & $2 \cdot 5 \pm 0.4$ & $296 \pm 38$ & $19 \cdot 1 \pm 4 \cdot 5$ \\
\hline $\begin{array}{l}2,13 \text { Tetrahydroxy- } \\
\text { c acid }\left(0.5 \mathrm{mg} \mathrm{ml}^{-1}\right)\end{array}$ & $2 \cdot 7 \pm 0 \cdot 6$ & $286 \pm 37$ & $19 \cdot 1 \pm 4 \cdot 8$ & $2 \cdot 6 \pm 0 \cdot 5$ & $312 \pm 40$ & $18.9 \pm 3.9$ \\
\hline
\end{tabular}

* Statistically significant differences from the control $(P<0.005)$. 
The same results were obtained when the same lipid supplements were added with the inoculum. In this case the growth of the fungus was partially inhibited by the epoxide compounds, e.g. methyl 9,10 epoxystearate and methyl 9,10:12,13 diepoxystearate inhibited growth measured as dry weight at day 6 by $40 \%$ and $50 \%$, respectively. However, these growth inhibitory effects did not persist beyond day 8 .

The lipid content of the different mycelia were unaffected by the different lipid sources used in the culture media whether or not aflatoxin production was stimulated. The lipid fractions studied were diglycerides, sterols, free fatty acids, triglycerides and sterol esters. The phospholipids phosphatidylcholine, phosphatidylethanolamine, phosphatidylinositol and phosphatidylserine were all detected in all the mycelia assayed, without any significant effect of the different lipid supplements.

The fatty acid composition of the free fatty acid, triglyceride and polar lipid fractions was also examined. In all cases $\mathbf{9 5 - 9 8 \%}$ of the fatty acids consisted of palmitic acid, oleic acid, linoleic acid, linolenic acid and stearic acid. The composition was unaffected by the different lipid sources whether or not they stimulated aflatoxin production.

These results confirmed our previous experiments obtained with cerulenin and tetrahydrocerulenin (Fanelli et al., 1983) and their analogues although other authors have found a strict correlation between total lipid of mycelia and aflatoxin production (Shih \& Marth, 1974).

Moreover, we have also reported (Fanelli et al., 1981) a great increase in total lipids in mycelia grown in culture media supplemented with a higher concentration of fatty acids and triglycerides without any corresponding increase in aflatoxin production.

All the experiments reported in the present work have been repeated with other toxigenic strains of $A$. flavus (strains ATCC 22584 and CF1 isolated in our Institute). Similar results were obtained with all the strains.

This study was supported by Cassa di Risparmio di Roma with the purchase of HPLC apparatus. The Authors were supported for 1981 by funds from Ministry of Education (40\%) and Faculty of Science of Rome University $(60 \%)$.

\section{REFERENCES}

D'Agnolo, G., Rosenfeld, I. S., Awaya, J., Ōmura, S. \& VAGelos, P. R. (1973). Specific inactivation of $\beta$-ketoacyl-acyl carrier protein synthetase. Biochimica et biophysica acta 326, 155-166.

Fanelli, C., FabBri, A. A. \& Passi, S. (1980). Growth requirements and lipid metabolism of Aspergillus flavus. Transactions of the British Mycological Society 75, 371-375.

Fanelli, C., Fabbri, A. A. \& Passi, S. (1981). Aflatoxin production by Aspergillus flavus during incubation with lipid sources in culture media. Transactions of the British Mycological Society 77, 416-419.

Fanelli, C., Fabbri, A. A., Finotit, E., Panfili, G. \& PAssi, S. (1983). Cerulenin and tetrahydrocerulenin: stimulating factors of aflatoxin biosynthesis. Transactions of the British Mycological Society (in the Press).

Nazzaro-Porro, M., Passi, S., Caprilli, F., BoniFORTI, L. \& LORETI, P. (1973). Attività lipolitica del Pityrosporum orbicolare in vivo e in vitro. Studio dei lipidi della superficie cutanea nella Pitiriasi versicolore. Bollettino Istituto Dermatologico San Gallicano (Roma) 8, 179-190.

Passi, S., Nazzaro-Porro, M., Boniforti, L. \& Giannotti, F. (1981 a). Analysis of the lipids and dioxin in chloracne due to tetrachloro-2,3,7,8-pdibenzodioxin. British Journal of Dermatology 105, 137-143.

Passi, S., Rothshilid-Boros, M. C., Fasella, P., Nazzaro-Porro, M. \& Whithouse, D. $(1981 b)$. An application of high performance liquid chromatography to analysis of lipids in archaeological samples. Journal of Lipid Research 22, 778-784.

PoCAR, D. (1966). Reazioni Organiche. Milano: Casa Editrice Ambrosiana.

Shih, C. N. \& MaRTh, E. H. (1974). Aflatoxin formation, lipid synthesis, and glucose metabolism by Aspergillus parasiticus during incubation with and without agitation. Biochimica et biophysica acta $\mathbf{3 3 8}$, 286-296. 